\title{
Mammalian Motoneuron Axon Targeting Requires Receptor Protein Tyrosine Phosphatases $\sigma$ and $\delta$
}

\author{
Noriko Uetani, ${ }^{1}$ Mélanie J. Chagnon, ${ }^{1}$ Timothy E. Kennedy, ${ }^{2}$ Yoichiro Iwakura, ${ }^{3}$ and Michel L. Tremblay ${ }^{1}$ \\ ${ }^{1}$ McGill Cancer Centre and Department of Biochemistry, McGill University, Montreal, Quebec, Canada H3G 1Y6, ${ }^{2}$ Centre for Neuronal Survival, Department \\ of Neurology and Neurosurgery, Montreal Neurological Institute, McGill University, Montreal, Quebec, Canada H3A 2B4, and ${ }^{3}$ Center for Experimental \\ Medicine, Institute of Medical Sciences, University of Tokyo, Tokyo 108-8639, Japan
}

The leukocyte common antigen-related (LAR) subfamily of receptor protein tyrosine phosphatases (RPTPs), LAR, RPTP- $\sigma$, and RPTP- $\delta$, regulate neuroendocrine development, axonal regeneration, and hippocampal long-term potentiation in mammals. In Drosophila, RPTPs are required for appropriate axon targeting during embryonic development. In contrast, deletion of any one of the three LARRPTP family members in mammals does not result in gross axon targeting defects. Both RPTP- $\sigma$ and RPTP- $\delta$ are highly expressed in the developing mammalian nervous system, suggesting they might be functionally redundant. To test this hypothesis, we generated RPTP- $\sigma$ and RPTP- $\delta(\mathrm{RPTP}-\sigma / \delta$ ) double-mutant mice. Although embryonic day $18.5 \mathrm{RPTP}-\sigma$ and RPTP- $\delta$ single-mutant embryos were viable, RPTP- $\sigma / \delta$ double mutants were paralyzed, were never observed to draw a breath, and died shortly after cesarean section. RPTP- $\sigma / \delta$ double mutants exhibit severe muscle dysgenesis and severe loss of motoneurons in the spinal cord. Detailed analysis of the projections of phrenic nerves in RPTP- $\sigma / \delta$ double mutants indicated that these motoneuron axons emerge normally from the cervical spinal cord, but stall on reaching the diaphragm. Our results demonstrate that RPTP- $\sigma$ and RPTP- $\delta$ complement each other functionally during mammalian development, and reveal an essential contribution of RPTP- $\sigma$ and RPTP- $\delta$ to appropriate motoneuron axon targeting during mammalian axonogenesis.

Key words: protein tyrosine phosphatase; tyrosine phosphorylation; axon targeting; axon guidance; motoneuron (motor neuron); phrenic; $\sigma ; \delta$

\section{Introduction}

Receptor protein tyrosine phosphatases (RPTPs) are key regulators of axon guidance in Drosophila (Johnson and Van Vactor, 2003). For example, loss-of-function mutants of leukocyte common antigen-related (LAR) subfamily RPTPs [Drosophila LAR (DLAR)] exhibit defects in motor axon guidance, midline axon crossing, and photoreceptor axon guidance (Desai et al., 1996; Krueger et al., 1996; Sun et al., 2000; Clandinin et al., 2001; Maurel-Zaffran et al., 2001; Desai and Purdy, 2003). There are three vertebrate homologs of DLAR: PTPRS (RPTP- $\sigma$ ), PTPRD (RPTP- $\delta$ ), and PTPRF (LAR) (Johnson and Holt, 2000; Johnson and Van Vactor, 2003).

\footnotetext{
Received June 27, 2005; revised April 18, 2006; accepted April 19, 2006.

This work was supported by funding from the Canadian Institutes of Health Research (CIHR) (MOP-42482 to M.L.T.). M.L.T. is a Chercheur National du Fonds de la Recherche en Santé du Québec (FRSQ) and a holder of the Jeanne and Jean-Louis Levesque Chair in Cancer Research. T.E.K. holds a FRSQ Chercheur-Boursier award. N.U. is a recipient of a CIHR-funded Chemical Biology Postgraduate Training award. M.J.C. is a recipient of a FRSQ Doctoral Training Award. We thank Eva Migon and Lisa Michelle Read for their help with excellent animal care, and Cortney Trott for genotyping mice. We also thank all members of the Tremblay laboratory for their valuable discussions. The monoclonal antibodies against Islet-1/2 (39.4D5) developed by Dr. Thomas M. Jessell and neurofilament (2H3) developed by Drs. Thomas M. Jessell and Jane Dodd were obtained from the Developmental Studies Hybridoma Bank developed under the auspices of the National Institute of Child Health and Human Development and maintained by the Department of Biological Sciences, University of lowa (lowa City, IA).

Correspondence should be addressed to Michel L. Tremblay, McGill Cancer Centre, McIntyre Medical Sciences Building, McGill University, 3655 Promenade Sir-William-0sler, Room 701, Montreal, Quebec, Canada H3G 1 Y6. E-mail: michel.tremblay@mcgill.ca.

D0I:10.1523/JNEUROSCI.0386-06.2006

Copyright $\odot 2006$ Society for Neuroscience $\quad 0270-6474 / 06 / 265872-09 \$ 15.00 / 0$
}

Type IIa RPTPs are characterized by variable numbers of extracellular Ig-like and type-III fibronectin (FNIII) repeats and two intracellular tandem phosphatase domains. The extracellular domains of this family resemble cell adhesion molecules (CAMs), suggesting that they play roles in cell-cell and cell-matrix interactions (Brady-Kalnay and Tonks, 1995; Beltran and Bixby, 2003).

In vertebrates, type IIa RPTPs are present in axons and growth cones (Tian et al., 1991; Desai et al., 1994; Stoker et al., 1995; Sommer et al., 1997; Schaapveld et al., 1998; Thompson et al., 2003). Although RNA interference-mediated knock-down has provided evidence that they contribute to motor axon guidance in chick (Stepanek et al., 2005), a role for LAR subfamily members in axon guidance during mammalian development has not been reported. Limited levels of LAR expression in the CNS are detected during development, and its absence results in minor defects in cholinergic innervation of the hippocampal dentate gyrus (Yeo et al., 1997; Van Lieshout et al., 2001). In contrast, RPTP $-\sigma$ and RPTP- $\delta$ are highly expressed in the developing mammalian nervous system (Yan et al., 1993; Mizuno et al., 1994; Sommer et al., 1997; Schaapveld et al., 1998). RPTP- $\sigma$-deficient mice exhibit abnormal development of the pituitary and neurological defects that include spastic movements and abnormal limb flexion (Elchebly et al., 1999; Wallace et al., 1999). Additionally, the absence of RPTP- $\sigma$ results in enhanced axon regeneration in both the peripheral and central nervous systems (McLean 
et al., 2002; Thompson et al., 2003; Saphieha et al., 2005). Mutant mice lacking an essential catalytic domain of RPTP- $\delta$ exhibit early growth retardation and neonatal mortality. In this case, the high mortality is likely attributable to insufficient food intake caused by motor dysfunction. RPTP- $\delta$-deficient mice that reach adulthood show enhanced hippocampal long-term potentiation and impaired spatial learning ability (Uetani et al., 2000).

The overlapping expression patterns of RPTP- $\sigma$ and RPTP- $\delta$ suggest that the phenotypes observed in single gene knock-outs may underestimate the contribution of type IIa RPTPs to mammalian neural development. Consistent with this, RNA interference knock-down suggested overlapping functions for LARRPTPs in cultured rat hippocampal neurons (Dunah et al., 2005). To address the possibility of functional redundancy in vivo, mice deficient for both RPTP- $\sigma$ and RPTP- $\delta$ were generated and characterized. Our findings demonstrate that RPTP- $\sigma$ and RPTP- $\delta$ are essential for the appropriate innervation of muscles by motoneurons during development of the murine peripheral nervous system.

\section{Materials and Methods}

Generation of RPTP- $\sigma / \delta$ double-mutant mice. Mutant mice lacking either RPTP- $\sigma$ or RPTP- $\delta$ have been described previously (Elchebly et al., 1999; Uetani et al., 2000). These animals were backcrossed for at least six generations to C57BL/6J. Double homozygous mutant mice were obtained by intercrossing double heterozygous parents. Noon on the day of the detection of the vaginal plug was considered embryonic day 0.5 (E0.5). To genotype RPTP- $\sigma$ and RPTP- $\delta$ alleles, tissue lysates from mice were used for PCR analysis with allele-specific primers: Sigma-WT-R2, 5' TAG TCA GAG CCC TCC ACA CCG-3'; Sigma-KO-F1, 5' -CAG CGA CCT CCA ACA CAC AAG-3'; Sigma-WT-F2, 5' -CAT TTC CAG TTC ACG GCA TGG C-3'; Delta-WT-R1, 5' -CTG GAA TTG TCT CAC TTT CCT C-3'; Delta-WT-F1, 5' -CCA GCA GAG GCA CAG AAA CTC-3'; Delta-PGK\#5, $5^{\prime}$-GAC TGC CTT GGG AAA AGC GCC TCC-3'.

RPTP- $\sigma$ wild-type and knock-out alleles are predicted to produce 781 and 1000 bp PCR products, respectively. RPTP- $\delta$ wild-type and knockout alleles are predicted to produce 620 and $380 \mathrm{bp}$ bands, respectively. Amplified bands were the expected size. Mice were kept under specific pathogen-free conditions in an environmentally controlled clean room at the Animal Resource Center of McGill University. All experiments were conducted according to the Canadian Council of Animal Care ethical guidelines for animal experiments.

Animals identified as "control" in this study include littermates with the following genotypes (RPTP- $\sigma^{+/+} / \delta^{+/+}, \mathrm{RPTP}-\sigma^{+/-} / \delta^{+/+}$, RPTP$\sigma^{+/+} / \delta^{+/-}$, RPTP $\left.-\sigma^{+/-} / \delta^{+/-}\right)$with all presenting identical normal (wild-type) phenotypes. Hence they were tabulated together for statistical analysis.

Histological analysis. Tissues were dissected and fixed in phosphate buffered $4 \%$ paraformaldehyde (PFA), left overnight in the same fixative, and then embedded in paraffin wax according to standard procedure. Serial $6 \mu \mathrm{m}$ paraffin sections were made and stained with hematoxylin and eosin (H\&E) or cresyl violet (Nissl stain). For every fourth section at the forelimb level (E18.5), the thickness of the dorsal epidermis and dermis was measured at three locations using AxioVision, version 4.0, software (Carl Zeiss, Oberkochen, Germany). The thickness of the diaphragm was measured on E16.5 sagittal sections at eye level in the same way. A total of three sections from each animal was measured and the mean value of these measurements was used as a single data value for statistical analysis by Student's $t$ test. Skeletal muscle was visualized in paraffin sections using an antibody against myosin heavy chain (MY32; Sigma, St. Louis, MO; 1:100 dilution; a biotinylated anti-mouse secondary antibody and peroxidase-labeled streptavidin; LSAB kit; DakoCytomation, Carpinteria, CA). The color reaction was developed using 3-3'-diaminobenzidine tetrahydrochloride (DAB) as a chromogen (SigmaFast DAB tablets; Sigma). Histological analyses were performed on E16.5 RPTP $-\sigma / \delta$ double mutants $(n=2)$ with control littermates $(n=2)$, and on E18.5 RPTP- $\sigma / \delta$ double mutants $(n=3)$ with their control littermates $(n=3), \operatorname{RPTP}-\sigma^{-1-} / \delta^{+/+}(n=2)$, $\mathrm{RPTP}-\sigma^{+/+} / \delta^{-1-}(n=2), \mathrm{RPTP}-\sigma^{+/-} / \delta^{-1-}(n=2)$, and RPTP$\sigma^{-1-} / \delta^{+/-}(n=2)$.

Quantification of motor neurons. E13 and E18.5 embryos were fixed in $4 \%$ PFA overnight. Whole E13 embryos were embedded in OCT compound (TissueTek; Sakura Finetek, Torrance, CA). Cervical spinal cords (C3-C5) were dissected from E18.5 embryos and embedded in paraffin. Ten micrometer serial cryostat and paraffin sections were prepared. The location of C3-C5 at E13 was determined morphologically based on surrounding tissue. Mouse anti-Islet-1/2 antibodies (39.4D5; Developmental Studies Hybridoma Bank, Iowa City, IA; supernatant, 1:50 dilution) and goat anti-choline acetyltransferase (ChAT) antibodies (Chemicon, Temecula, CA; 1:100 dilution) were used to identify motoneurons in the E13 and E18.5 spinal cords, respectively. Sections were visualized using secondary antibodies coupled to Alexa 488 (Invitrogen, San Diego, $\mathrm{CA}$ ), and photographed using a Zeiss Axioskop2 Plus microscope.

Islet-1/2- and ChAT-immunopositive motoneurons were counted independently on right and left hemiventral columns in every fourth section. A total of 10 hemiventral columns from each animal were counted, and the mean value of these counts was used as an individual data point for statistical analysis by Student's $t$ test. At E13, RPTP- $\sigma / \delta$ double mutants $(n=3)$ were analyzed with their control $(n=5)$ littermates. At E18.5, RPTP- $\sigma / \delta$ double mutants $(n=3)$ were analyzed with their littermates RPTP- $\sigma^{+/+} / \delta^{+/+}(n=4)$, RPTP- $\sigma^{+/+} / \delta^{-1-}(n=3)$, RPTP$\sigma^{-l-} / \delta^{+/+}(n=2), \mathrm{RPTP}-\sigma^{+/-} / \delta^{-/-}(n=2)$, and RPTP- $\sigma^{-l-} / \delta^{+\prime-}$ $(n=4)$.

Whole-mount diaphragm staining. To visualize peripheral nerves, whole E12 embryos and thoracic cages dissected from E13.5 and E15.5 embryos were fixed in methanol/dimethylsulfoxide (DMSO) $(4: 1)$ at $4^{\circ} \mathrm{C}$ overnight. Tissues were then immersed in methanol/DMSO/ $\mathrm{H}_{2} \mathrm{O}_{2}$ (4: $1: 1)$ at room temperature for $5-10 \mathrm{~h}$ to block endogenous peroxidase activity, and rehydrated in 50\% methanol and PBS. E12 embryos were embedded in OCT compound, and sagittal sections were cut with a cryostat until heart and liver were visible. The remaining E12 embryonic tissue was immersed in PBS to remove excess OCT and then blocked in PBS containing 5\% skimmed milk, 0.5\% Triton X-100 (PBSMT). The embryos were incubated in $2 \mathrm{ml}$ of PBSMT with the $2 \mathrm{H} 3$ monoclonal antibody against neurofilament (ascites; 1:2000 dilution; $4^{\circ} \mathrm{C}$ overnight; Developmental Studies Hybridoma Bank) (Dodd et al., 1988). After washing with $4 \mathrm{ml}$ of PBSMT for $1 \mathrm{~h}$ at room temperature three times, the embryos were incubated with horseradish peroxidase-conjugated antimouse IgG (1:10,000 dilution) (Jackson ImmunoResearch, West Grove, PA) in PBSMT overnight at $4^{\circ} \mathrm{C}$. They were then washed with $4 \mathrm{ml}$ of PBSMT for $1 \mathrm{~h}$ at room temperature six times, and thoracic cages were soaked in DAB substrate solution to develop the color reaction (SigmaFast DAB tablets; Sigma). Stained diaphragms were dissected from E13.5 and E15.5 thoracic cages in PBS, and dehydrated in an ethanol series. After xylene substitution, diaphragms were mounted on slides. Stained E12 embryos were then dehydrated in methanol and substituted in benzyl alcohol (Sigma) and benzyl benzonate (Sigma) (1:2). Stained diaphragms were photographed and branch points on the sternocostal phrenic nerve were counted using AxioVision, version 4.0, software. E12 RPTP- $\sigma / \delta$ double mutants $(n=3)$ were analyzed with control $(n=4)$ littermates. E13.5 RPTP- $\sigma / \delta$ double mutants $(n=2)$ were analyzed with control $(n=2), \operatorname{RPTP}-\sigma^{-/-} / \delta^{+/+}(n=2), \operatorname{RPTP}-\sigma^{+/+} / \delta^{-/-}(n=3)$, RPTP- $\sigma^{-1-} / \delta^{+l-}(n=1)$, and RPTP- $\sigma^{+l-} / \delta^{-1-}(n=2)$ littermates. E15.5 RPTP- $\sigma / \delta$ double mutants $(n=2)$ were analyzed with control $(n=3), \mathrm{RPTP}-\sigma^{-l-} / \delta^{+/+}(n=3), \mathrm{RPTP}-\sigma^{+/+} / \delta^{-l-}(n=2)$, RPTP$\sigma^{-l-} / \delta^{+l-}(n=2)$, and RPTP- $\sigma^{+/-} / \delta^{-l-}(n=3)$ littermates.

\section{Results}

\section{RPTP $\sigma / \delta$ double-mutant mice die at birth}

RPTP- $\sigma$ and RPTP- $\delta(\mathrm{RPTP}-\sigma / \delta$ ) double-mutant mice were generated by breeding adults heterozygous for both RPTP- $\sigma$ and RPTP- $\delta\left(\mathrm{RPTP}-\sigma^{+/-} / \delta^{+/-} \times \mathrm{RPTP}^{-} \sigma^{+/-} / \delta^{+/-}\right)$. Pups were genotyped using PCR with gene-specific primers (Fig. 1A). Although each of the single knock-outs is viable at birth, live RPTP$\sigma / \delta$ double mutants were not found in litters of newborn pups at 
A

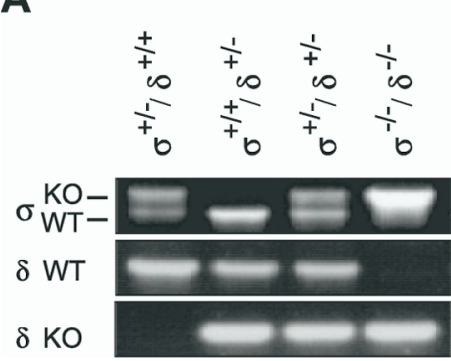

B

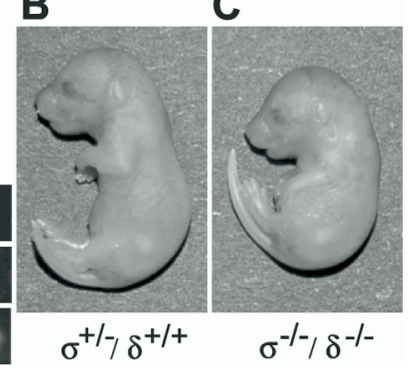

Figure 1. Targeted disruption of the RPTP- $\sigma$ and RPTP- $\delta$ genes. A, PCR-amplified DNA bands using RPTP- $\sigma$ and RPTP- $\delta$ allele-specific primers are shown. In RPTP- $\sigma$ allele, the amplified knock-out (KO) and wild-type (WT) allele-specific DNA bands are indicated. B, C, E18.5 RPTP- $\sigma / \delta$ double mutants exhibit ptotic postures such as hunchback and wrist drop $(C)$, which are not exhibited by non-double-mutant control littermates $(\boldsymbol{B})$ after cesarean section.

Table 1. Offspring of RPTP- $\sigma$ and RPTP- $\delta$ mutant mice derived from parental animals heterozygous for both mutations

\begin{tabular}{lcccc}
\hline & \multicolumn{4}{c}{ Observed ratio (\%) } \\
\cline { 3 - 5 } Genotype $(\sigma \cdot \delta)$ & Predicted ratio (\%) & E18 & P0 & 4 Weeks \\
\hline$+/+\cdot+/+$ & 6.25 & 6.85 & 9.68 & 7.53 \\
$+/-\cdot+/+$ & 12.50 & 10.96 & 19.35 & 25.09 \\
$-/-\cdot+/+$ & 6.25 & 4.11 & 5.53 & 3.58 \\
$+/+\cdot+/-$ & 12.50 & 12.33 & 8.29 & 17.20 \\
$+/-\cdot+/-$ & 25.00 & 32.88 & 21.20 & 35.84 \\
$-/-\cdot+/-$ & 12.50 & 9.59 & 15.67 & 2.87 \\
$+/+\cdot-/-$ & 6.25 & 9.59 & 24.29 & 6.45 \\
$+/-\cdot-/-$ & 12.50 & 8.22 & 9.22 & 1.43 \\
$-/-\cdot-/-$ & 6.25 & 5.48 & $3.23^{a}$ & 0.00 \\
& & $(n=73)$ & $(n=217)$ & $(n=279)$ \\
\hline
\end{tabular}

${ }^{a}$ Ratio includes animals found dead at birth.

postnatal day $0(\mathrm{P} 0)(n=217)$ (Table 1$)$. Furthermore, RPTP$\sigma^{-/-} / \delta^{+/-}$and $\mathrm{RPTP} \sigma^{+/-} / \delta^{-/-}$mice had slightly higher mortality rates compared with either single mutant. Within $4 \mathrm{~d}$ of birth, 55\% of RPTP- $\sigma^{-1-} / \delta^{+/-}(n=18)$ and 71\% of RPTP- $\sigma^{+/-} /$ $\delta^{-l-}(n=14)$ pups died, whereas $44.4 \%$ of RPTP- $\sigma^{-/-} / \delta^{+/+}$ $(n=18)$ and $14.3 \%$ of RPTP- $\sigma^{+/+} / \delta^{-1-}(n=21)$ died in the same period. Mice heterozygous for either gene had mortality rates not significantly different from wild-type littermates $\left(\mathrm{RPTP}-\sigma^{+/+} / \delta^{+/+}, 8.7 \%\right.$; RPTP- $\sigma^{+/-} / \delta^{+/+}, 13.6 \%$; RPTP- $\sigma^{+/+} /$ $\left.\delta^{+/-}, 5.9 \%\right)$. These findings suggest that RPTP- $\sigma$ and RPTP- $\delta$ exhibit some functional complementarity during development.

To investigate whether RPTP- $\sigma / \delta$ double-mutant mice died before or after birth, cesarean sections were performed at E18.5. Approximately one-sixteenth $(5.48 \% ; n=73)$ were RPTP- $\sigma / \delta$ double mutant, slightly less than the expected Mendelian ratio, indicating that the RPTP- $\sigma / \delta$ double mutants are viable to late embryogenesis. While, non-double-mutant E18.5 littermates begin to breathe immediately after cesarean section, RPTP- $\sigma / \delta$ double-mutant embryos were never observed to take a breath and died shortly after cesarean section. Furthermore, RPTP- $\sigma / \delta$ double mutants were never observed to move and display kyphosis (hunchback) and carpoptosis (wrist drop) with 100\% penetrance $(n=12)$ as shown in Figure $1 C$. Histological analysis revealed that the alveoli of E18.5 RPTP- $\sigma / \delta$ double-mutant mice $(n=3)$ were tightly compressed (Fig. 2C), consistent with their inability to breathe. We conclude that RPTP $\sigma / \delta$ double mutants die immediately after birth and that death is likely attributable to respiratory failure.

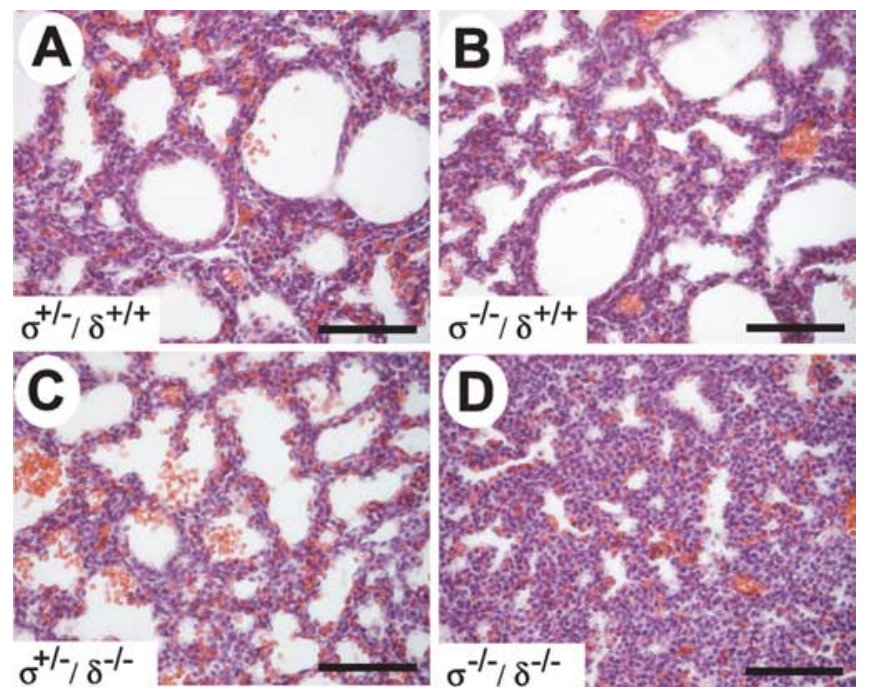

Figure 2. Histological analyses of the lung. $A-D$, Histology of H\&E-stained lung sections prepared from E18.5 embryos 30 min after cesarean section. The alveoli of RPTP- $\sigma / \delta$ double mutants were tightly compressed $(\boldsymbol{D})$, and incompletely extended alveoli were seen in RPTP$\sigma^{+/-} / \delta^{-/-}$lung $(\boldsymbol{C})$, compared with RPTP- $\sigma^{+/-} / \delta^{+/+}(\boldsymbol{A})$ and RPTP- $\sigma^{-/-} / \delta^{+/+}(\boldsymbol{B})$ littermates. Scale bars, $50 \mu \mathrm{m}$.

\section{Histological analysis of skin, adipose tissue and skeletal muscle}

To examine the effects of the mutations on tissue structure, an extensive histological survey was performed. The skin of RPTP$\sigma / \delta$ double-mutant embryos was abnormal with a semitransparent appearance that was obvious from E15. Although the thickness of the epidermis was not altered in RPTP- $\sigma / \delta$ double mutants (controls, $42 \pm 8 \mu \mathrm{m}, n=18$; RPTP- $\sigma / \delta$ double mutants, $43 \pm 9 \mu \mathrm{m}, n=18)$, the dermis of RPTP- $\sigma / \delta$ double mutants was thinner (control, $109 \pm 21 \mu \mathrm{m}, n=18$; RPTP $-\sigma / \delta$ double mutants, $83 \pm 14 \mu \mathrm{m}, n=18 ; p<0.001$ ) and hair follicles were not fully developed at E18.5 in comparison with control non-double-mutant littermates (Fig. $3 A-D$ ). Subcutaneous tissues were enlarged, and the compartmentalization of brown adipose tissue was less obvious in RPTP- $\sigma / \delta$ double mutants (Fig. $3 E, G$, indicated by $\left.{ }^{* *}\right)$. Furthermore, immunohistochemical analyses using anti-myosin heavy chain antibodies revealed a reduction in the mass of dorsal axial skeletal muscles and limb muscles (Fig. $3 E-J$ ). In E18.5 RPTP- $\sigma / \delta$ double-mutant embryos, we observed that skeletal muscle fibers were smaller in diameter, with their nuclei centrally localized along the fiber, suggesting the muscles remained immature with their development halted at an early stage of myotube formation (Fig. $3 K, L$ ). These phenotypes, revealed using histological and immunohistochemical staining, were identical in each of the three E18.5 RPTP$\sigma / \delta$ double-mutant samples analyzed. Although only two E16.5 embryos were analyzed for each genotype, the mean thickness of the diaphragm of these RPTP- $\sigma / \delta$ double-mutant mice was thinner compared with those of wild-type littermates (RPTP- $\sigma^{+/+}$/ $\delta^{+/+}, 197 \pm 15 \mu \mathrm{m}, n=27$; RPTP- $\sigma / \delta$ double mutants, $110 \pm 17$ $\mu \mathrm{m}, n=27 ; p<0.001$ ) (Fig. $3 M-P$ ). Together, these results suggest that the respiratory insufficiency in the double mutants was attributable to skeletal muscle defects, likely caused by the absence of motoneuron innervation, as described below.

Histological differences were not detected in H\&E-stained E18.5 heart, liver, kidney, colon, thymus, or spleen of RPTP- $\sigma / \delta$ double mutants (data not shown). In addition, sagittal sections of E18.5 brain were also examined by H\&E stain. Although RPTP- $\sigma$ 


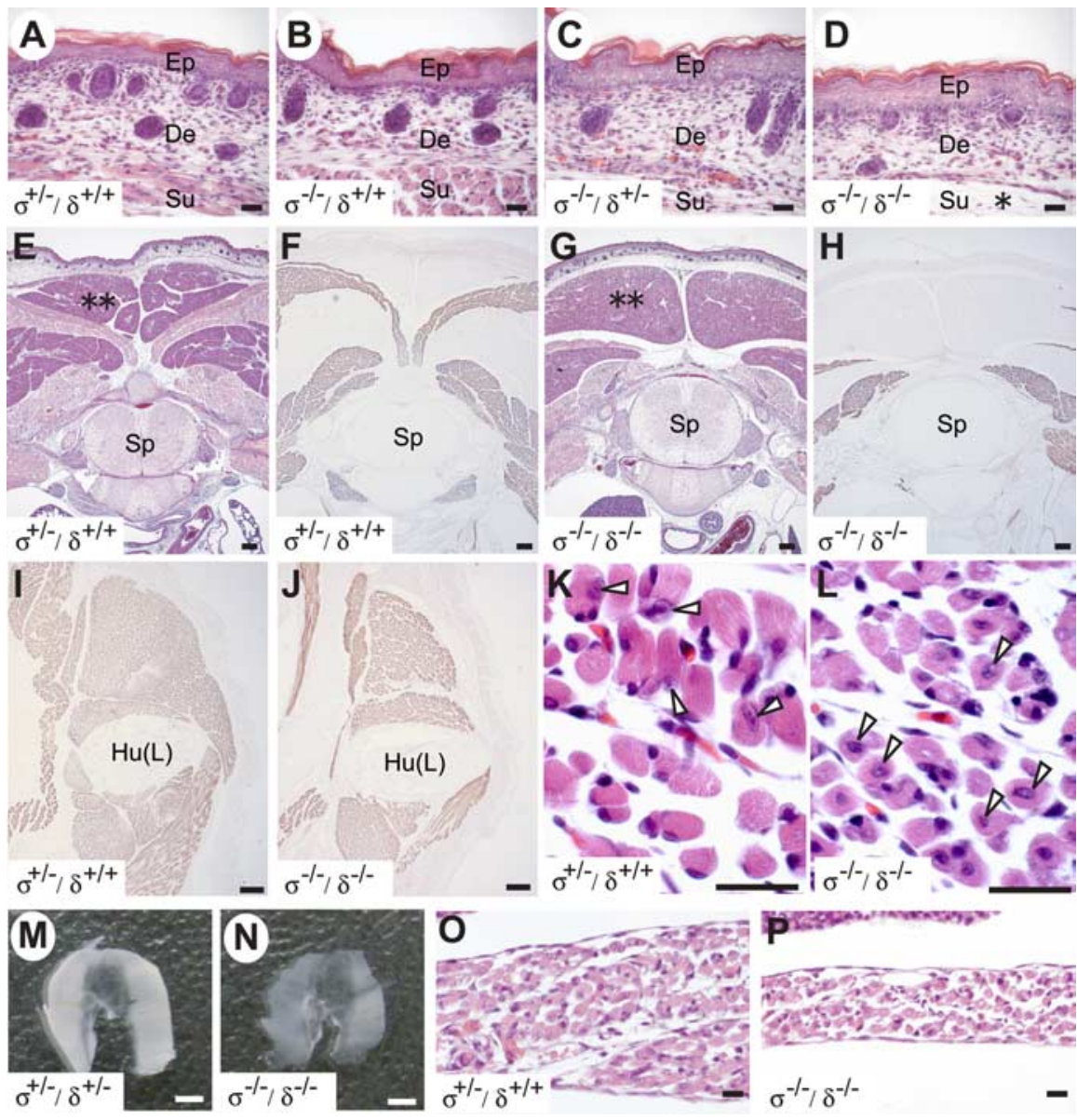

Figure 3. RPTP- $\sigma / \delta$ double-mutant embryos exhibit abnormal muscle development. Comparable transverse sections of E18.5 embryos at forelimb level $(\boldsymbol{A}-\boldsymbol{L})$ and sagittal sections of $\mathrm{E} 16$ embryos $(\boldsymbol{O}, \boldsymbol{P})$ were stained with $\mathrm{H} \& \mathrm{E}(\boldsymbol{A}-\boldsymbol{D}, \boldsymbol{E}, \boldsymbol{G}, \boldsymbol{K}, \boldsymbol{L}, \mathbf{0}, \boldsymbol{P})$, and skeletal muscles were immunohistochemically visualized with anti-myosin heavy chain antibodies $(\boldsymbol{F}, \boldsymbol{H}, \boldsymbol{I}, \boldsymbol{J})$. $\boldsymbol{A}-\boldsymbol{D}$ illustrate skin from the embryos' backs. In the RPTP- $\sigma / \delta$ double mutant $(\boldsymbol{D})$, the dermis was thinner than in non-double-mutant littermates $(\boldsymbol{A}-\boldsymbol{C})$, and immature hair follicles were distributed under the epidermis. Subcutaneous tissue was enlarged dropsically in RPTP$\sigma / \delta$ double mutants $\left(\boldsymbol{D}\right.$; indicated by $\left.{ }^{*}\right) . \boldsymbol{E}-\boldsymbol{H}$, Dorsal axial skeletal muscle mass was markedly reduced, and the conformation of brown adipose tissue was not well organized in RPTP- $\sigma / \delta$ double mutants $(\boldsymbol{G}, \boldsymbol{H})$ compared with non-double-mutant littermates $(\boldsymbol{E}, \boldsymbol{F})$ (brown adipose tissues are indicated by $\left.{ }^{* *}\right) . \boldsymbol{I}, \boldsymbol{J}$, Forelimb skeletal muscle mass was also relatively smaller in size in RPTP- $\sigma / \delta$ double mutants $(\boldsymbol{J})$ than in control littermates $(\boldsymbol{I}) . \boldsymbol{K}, \boldsymbol{L}$, High magnification of forelimb skeletal muscle. Muscle nuclei are indicated by white arrowheads. In RPTP- $\sigma / \delta$ double mutants, muscle fibers with central nuclei were observed in greater abundance, and the muscle fibers were smaller than those of the non-double-mutant littermates $(\boldsymbol{K})$. $\boldsymbol{M}-\boldsymbol{P}$ illustrate the diaphragm dissected from a control littermate $(\boldsymbol{M})$ and a RPTP- $\sigma / \delta$ double mutant $(\boldsymbol{N})$ at E18.5. Cross sections of the diaphragm of an E16 RPTP- $\sigma / \delta$ double-mutant $(\boldsymbol{P})$ and a non-double-mutant littermate $(\boldsymbol{0})$, revealed a thinner diaphragm in the RPTP- $\sigma / \delta$ double mutant. Scale bars: $\boldsymbol{A}-\boldsymbol{D}, \boldsymbol{K}, \boldsymbol{L}, \mathbf{O}, \boldsymbol{P}, 10 \mu \mathrm{m} ; \boldsymbol{E}-\boldsymbol{J}, 100 \mu \mathrm{m} ; \boldsymbol{M}, \boldsymbol{N}, 1 \mathrm{~mm}$. Ep, Epidermis; De, dermis; Su, subcutaneous tissue; $\mathrm{Sp}$, spinal cord; $\mathrm{Hu}(\mathrm{L})$, left humerus.

and RPTP- $\delta$ are highly expressed in the developing brain, the gross anatomy of the brain including olfactory bulb, forebrain, hippocampus, cortex, and cerebellum appeared normal in RPTP$\sigma / \delta$ double mutants (data not shown).

\section{Loss of spinal motoneurons in RPTP- $\sigma / \delta$ double mutants}

RPTP- $\sigma / \delta$ double-mutant embryos did not move after cesarean section and appeared paralyzed (Fig. $1 C$ ). This phenotype is often associated with motoneuron defects, including aberrant neuromuscular junction formation (Misgeld et al., 2002; Brandon et al., 2003). RPTP- $\sigma$ and RPTP- $\delta$ are both highly expressed by spinal motoneurons during embryogenesis (Sommer et al., 1997; Schaapveld et al., 1998). To explore the possibility that motoneuron development may be disrupted by loss of RPTP $-\sigma$ and RPTP- $\delta$ function, transverse sections of spinal cords were examined by Nissl stain (Fig. 4). At E18.5, motoneurons were readily identified by their large cell bodies, large nucleolus, and enriched cellular Nissl bodies in the spinal cords of wild-type embryos (Fig. 4C).

In contrast, only a few morphologically abnormal motoneurons, exhibiting smaller cytoplasm with Nissl bodies and an indistinct nucleolus, were found in E18.5 RPTP- $\sigma / \delta$ double mutants (Fig. $4 D$, arrows). No obvious abnormalities were observed in the dorsal root ganglia (DRGs) (Fig. $4 E, F)$ or sympathetic ganglia (SGs) (Fig. 4G,H). Expression of the motoneuron-specific markers, Islet-1/2 and ChAT (Tsuchida et al., 1994; Pfaff et al., 1996; Helmbacher et al., 2000), was then examined on transverse sections of E13 and E18.5 spinal cords at the level of the third (C3) and fifth (C5) cervical vertebrae, respectively (Fig. 5A-D). Although the number of Islet-1/2-immunopositive motoneurons per hemiventral motor column appeared normal in RPTP- $\sigma / \delta$ double mutants at E13 (Fig. $5 E$ ), the number of ChAT-immunopositive motoneurons detected in RPTP $-\sigma / \delta$ double mutants at E18.5 was significantly reduced (Fig. $5 F,{ }^{* *} p<0.0001$ ). These findings identify a major motoneuron deficit in RPTP- $\sigma / \delta$ double mutants that occurs late in embryogenesis between E13 and E18.5, during motoneuron axon extension. Additionally, a smaller but significant decrease in the number of ChAT-immunopositive motoneurons was also detected in RPTP- $\sigma^{-1-}$, $\delta^{+/-}$embryos compared with wild-type or embryos mutant for either RPTP- $\sigma$ or RPTP- $\delta$ alone (Fig. $5 F,{ }^{*} p<0.001$ ). That a single gene dose of RPTP- $\sigma$ is sufficient for levels of motoneuron survival in RPTP$\sigma^{+/-} / \delta^{-1-}$ that are not different from control, suggests that RPTP- $\sigma$ may make a larger essential contribution to motoneuron survival than does RPTP- $\delta$.

\section{Altered innervation of the diaphragm by the phrenic nerve in RPTP- $\sigma / \delta$ double mutants}

Motoneurons depend on target-derived trophic support to survive. During late embryogenesis, cell death matches the number of motoneurons with the size of the muscle targets being innervated (Banks and Noakes, 2002). We hypothesized that defects in the ability of motoneurons to reach and innervate muscle targets might contribute to the motoneuron loss detected in RPTP- $\sigma / \delta$ double mutants (Figs. 4, 5). To test this, we examined the projection of the phrenic nerve at various developmental stages using whole-mount immunochemistry and a neurofilament (NF) antibody (2H3). The phrenic nerve contains motor axons that originate in the spinal cord between $\mathrm{C} 3$ and $\mathrm{C} 5$ and extend to the diaphragm. It then forms three characteristic branches on the surface of the diaphragm: two sternocostal branches and one 


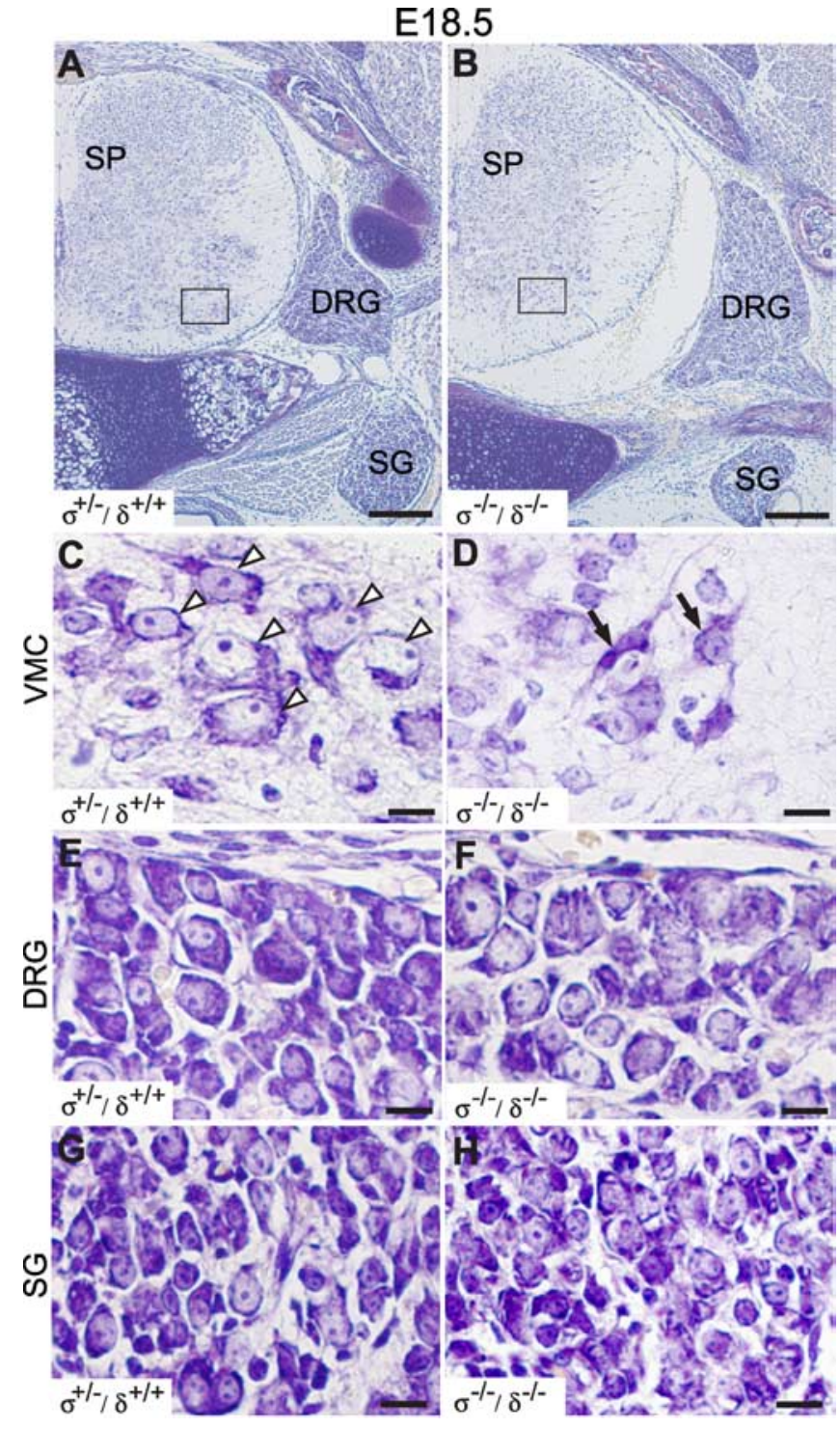

Figure 4. RPTP- $\sigma / \delta$ double mutants exhibit major defects in motoneurons but not DRG or $S G$ neurons. $\boldsymbol{A}, \boldsymbol{B}$, Nissl-stained spinal cord, DRG, and SG at the forelimb level are shown. $\boldsymbol{C}, \boldsymbol{D}$, High-magnification views of ventral horn motor columns from the regions framed in $\boldsymbol{A}$ and $\boldsymbol{B}$, respectively. Multiple motoneurons containing a large nucleolus are readily visible in the nondouble-mutant littermate ( $\boldsymbol{C}$, arrowheads). In contrast, RPTP- $\sigma / \delta$ double mutants contained reduced numbers of large motoneurons and degenerating motoneurons in the ventral horn of the spinal cord ( $\boldsymbol{D}$, arrows) compared with non-double-mutant littermates ( $\boldsymbol{C}$. $\boldsymbol{E}$ and $\boldsymbol{F}$, and $\boldsymbol{G}$ and $\boldsymbol{H}$ illustrate high-magnification views of DRG and SG, respectively. Morphologically, there were no significant differences in DRG and SG between each genotype. Scale bars: $A, B, 100 \mu \mathrm{m}$; $\boldsymbol{C}-\boldsymbol{H}, 10 \mu \mathrm{m}$. SP, Spinal cord; VMC, ventral motor column.

crural branch (a schematic is included in the supplemental material, available at www.jneurosci.org). In E10.5 RPTP- $\sigma / \delta$ double mutants, the phrenic nerve descends normally from the spinal cord (data not shown) and reaches the diaphragm at E12 $(n=3)$ (Fig. 6A). However, in E13.5 RPTP- $\sigma / \delta$ double-mutant embryos, the phrenic motor axons extend aberrantly on the surface of the diaphragm (Fig. $6 E, F)(n=2)$. Although the phrenic nerve appears to reach the appropriate initial location on the diaphragm, the two main sternocostal branches that normally defasciculate from the main nerve appear to have retracted (Fig. 6F, arrowhead), and only a tiny residual projection extends toward the crus (Fig. 6E, F, white arrowheads). These phrenic nerve abnormalities were identical in the two individual E13.5 RPTP- $\sigma / \delta$ double

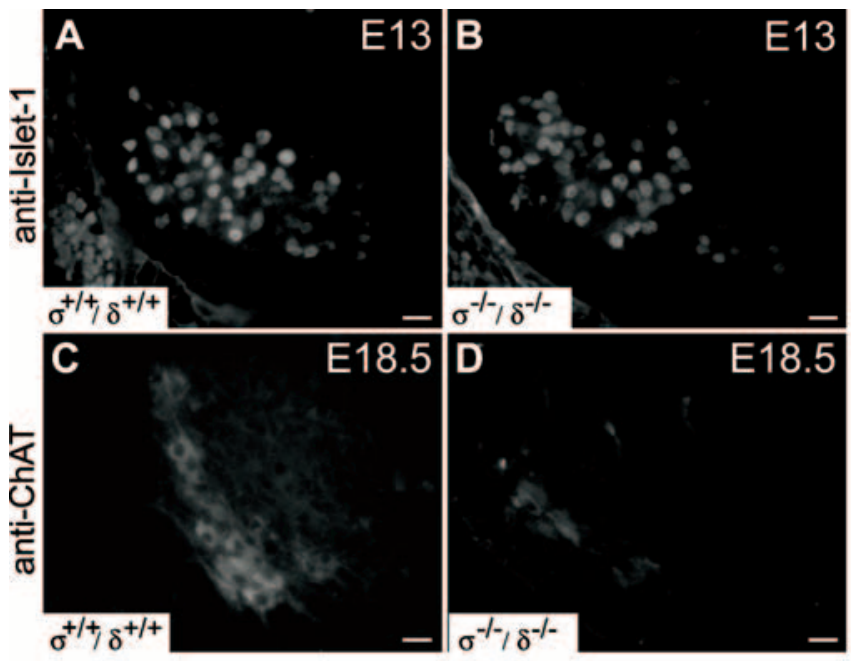

$\mathbf{E}$

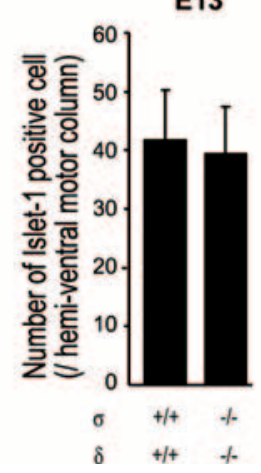

$\mathbf{F}$

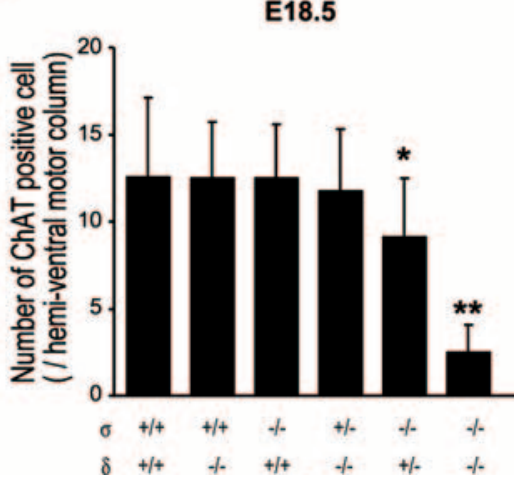

Figure 5. Loss of spinal motoneurons in RPTP- $\sigma / \delta$ double mutants. $A-D$, Islet- $1 / 2$ and ChAT immunofluorescence identifies ventral motoneurons in spinal cords (C3-C5) at E13 $(A, B)$ and E18.5 $(\boldsymbol{C}, \boldsymbol{D})$, respectively. At E13, similar populations of Islet-1/2-immunopositive motoneurons were detected in both wild-type and RPTP- $\sigma / \delta$ double mutants $(\boldsymbol{A}, \boldsymbol{B})$. $\boldsymbol{E}$, The number of Islet-1/2-immunopositive cells showed no significant difference ( $p=0.223$ ). At E18, ChAT-immunopositive motoneurons were seldom detected in E18.5 RPTP- $\sigma / \delta$ double mutants $(\boldsymbol{C}, \boldsymbol{D})$. $\boldsymbol{F}$, Quantitative analysis revealed that numbers of ChAT-immunopositive cells were significantly decreased in RPTP- $\sigma^{-1-} / \delta^{+/-}\left({ }^{*} p<0.001\right)$ and RPTP- $\sigma / \delta$ double mutants $\left({ }^{* *} p<0.0001\right)$. Error bars indicate SD. Scale bars: $A-D, 10 \mu \mathrm{m}$.

mutants examined. Furthermore, analyses of E15.5 $(n=2)$ and E18.5 $(n=3)$ double mutants revealed the complete absence of sternocostal branches on the diaphragm (E15.5) (Fig. 7E,F) (E18.5) (data not shown). Each of the total of seven RPTP- $\sigma / \delta$ double mutants analyzed (E13.5, E15.5, and E18.5) exhibited aberrant phrenic nerve phenotypes, consistent with the conclusion that these phrenic nerve defects are $100 \%$ penetrant in the absence of RPTP- $\sigma / \delta$ function. At E13.5 and E15.5, the capillaceous nerves normally defasciculate from the major sternocostal branches (Figs. 6C, 7A,B); however, capillaceous nerves were seldom observed in either the RPTP- $\sigma^{-1-} / \delta^{+/-}$(data not shown) or RPTP- $\sigma^{+/-} / \delta^{-1-}$ genotypes (Figs. $6 D, 7 C, D$ ). In contrast, the innervation of the diaphragm in RPTP- $\sigma$ and RPTP- $\delta$ single-mutant littermates appeared normal (Fig. 7G,H). To further substantiate these observations, we performed quantitative analysis on anti-NF-stained diaphragms at E15.5 by counting each nerve branch point. As shown in Figure 7I, the total number of branch points was decreased in RPTP- $\sigma^{+/-} / \delta^{-1-}(n=3)$ and RPTP- $\sigma^{-1-} / \delta^{+-}(n=2)$ embryos compared with non-double mutants, including the RPTP- $\sigma(n=3)$ and RPTP- $\delta(n=2)$ single mutants. 


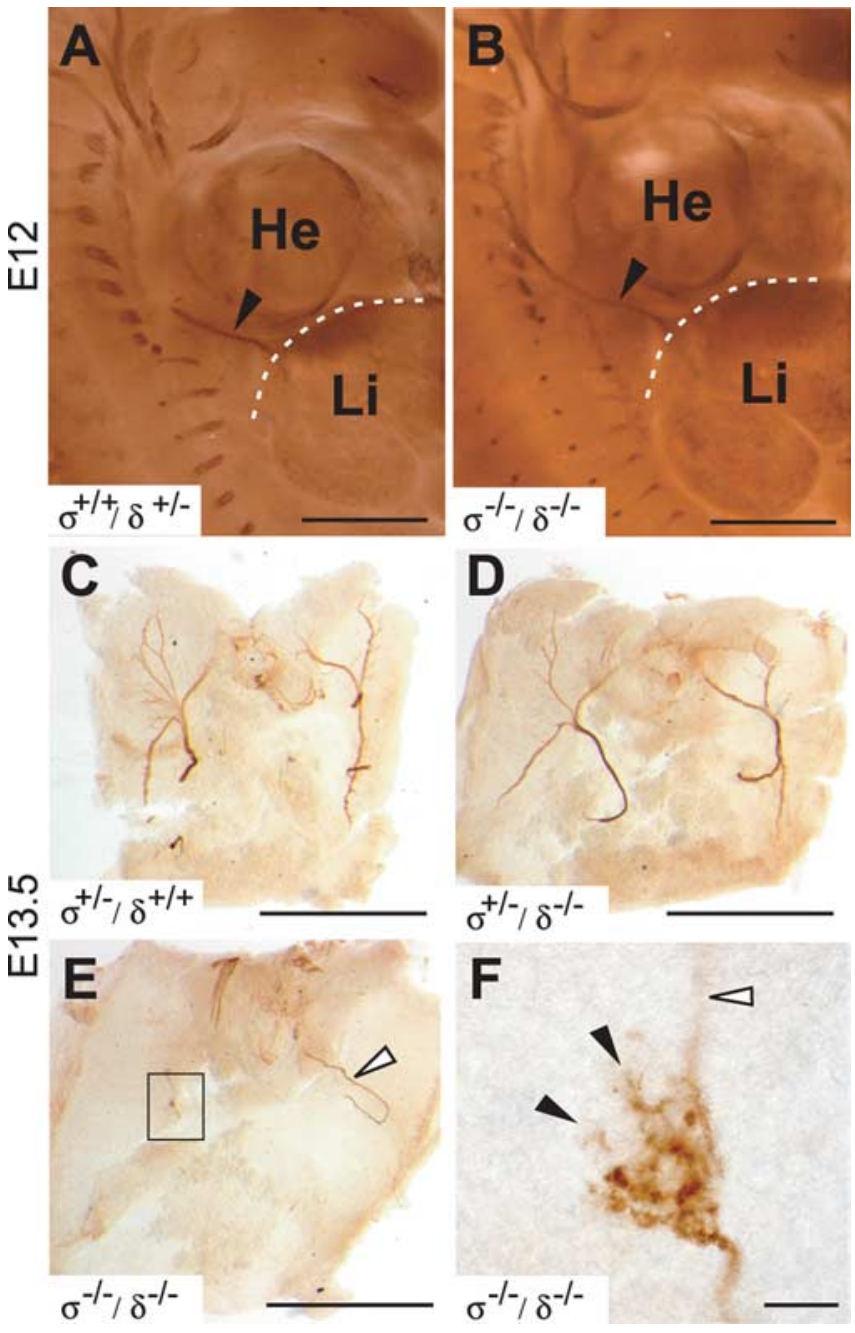

Figure 6. Aberrant innervation of the diaphragm in RPTP- $\sigma / \delta$ double mutants. Tissues were immunohistochemically labeled with anti-neurofilament antibodies (2H3). $\boldsymbol{A}, \boldsymbol{B}$, Sagittal views of non-double-mutant littermates RPTP- $\sigma^{+/+} / \delta^{+/-}(\boldsymbol{A})$ and RPTP- $\sigma^{-1-} / \delta^{-1-}$ $(\boldsymbol{B})$ at E12 are shown. Dotted lines indicate the diaphragm. Phrenic nerves (arrowheads) extended from cervical spinal cord and onto the diaphragm normally in the RPTP- $\sigma / \delta$ double mutant at $\mathrm{E} 12(\boldsymbol{B})(n=3) . \boldsymbol{C}-\boldsymbol{F}$, By E13.5, phrenic nerves branched out into three major nerves on the diaphragm of control RPTP- $\sigma^{+/-} / \delta^{+/+}(C)$; however, only one tiny nerve was seen to extend onto the diaphragm of RPTP- $\sigma^{-1-} / \delta^{-1-}(\boldsymbol{E})(n=2)$. The number of capillaceous nerves found to defasciculate from the major nerve trunk onto the diaphragm was slightly less in E13.5 RPTP- $\sigma^{+/-} / \delta^{-1-}$ mice $(\boldsymbol{D})(n=1)$. $\boldsymbol{F}$, High-magnification view of the frame in $\boldsymbol{E}$. Retracting sternocostal nerves are indicated by black arrowheads. Crural nerves are indicated by white arrowheads. Scale bars, $1 \mathrm{~mm}$. He, Heart; Li, liver.

Comparison of these findings with Figure $5 F$ indicates that the defect in branching is more sensitive to RPTP loss of function than is motoneuron survival: E18.5 RPTP $-\sigma^{+/-} / \delta^{-/-}$exhibit no significant difference in motoneuron number compared with control, whereas E18.5 RPTP $-\sigma^{-1-} / \delta^{+/-}$exhibit a modest, albeit significant, reduction of the number of motoneurons, $\sim 70 \%$ of control (Fig. $5 F$ ). In contrast, E18.5 double knock-out RPTP- $\sigma^{-/-}$/ $\delta^{-l-}$ exhibit severely reduced numbers of motoneurons, $\sim 20 \%$ of control, and no branching from the sternocostal phrenic nerve. Although these findings suggest a relationship between innervation and survival, we have not ruled out the possibility that these two phenotypes may be dissociable. The intermediate nerve branch phenotype found in RPTP $-\sigma^{-1-} / \delta^{+/-}$and RPTP$\sigma^{+/-} / \delta^{-1-}$ embryos provides evidence that RPTP- $\sigma$ and RPTP- $\delta$ have at least partially redundant functions and normally make an additive contribution to the branching of phrenic projections. We conclude that RPTP- $\sigma$ and RPTP- $\delta$ make an essential functional contribution to normal muscle innervation by motoneurons. Table 2 provides a summary of the quantitative analyses of the various phenotypes described.

\section{Discussion}

Here, we demonstrate that RPTP- $\sigma$ and RPTP- $\delta$ make a complementary contribution to motoneuron axon targeting during mammalian development. In the absence of either RPTP- $\sigma$ or RPTP- $\delta$, mice exhibit severe growth retardation, increased postnatal lethality, and motor dysfunction (Elchebly et al., 1999; Wallace et al., 1999; Uetani et al., 2000). Unlike in invertebrates, in which it has been shown that LAR-RPTP loss of function causes defects in axon extension by motoneurons (Desai et al., 1996, 1997; Krueger et al., 1996), photoreceptors (Garrity et al., 1999; Newsome et al., 2000), and commissural neurons (Sun et al., 2000 ), mutation of RPTP- $\sigma$ or RPTP- $\delta$ has not been found to generate gross defects in axon guidance in mammals. Among the three members of the mammalian LAR-RPTP subfamily, LAR is most broadly expressed and, in particular, is expressed in many non-neural tissues. In contrast, RPTP- $\sigma$ and RPTP- $\delta$ are both expressed in the CNS during neural development, often by the same cell types (Yan et al., 1993; Mizuno et al., 1994; Sommer et al., 1997; Schaapveld et al., 1998). We postulated that RPTP- $\sigma$ and RPTP- $\delta$ likely play important roles during neural development but that they may compensate for each other functionally in single RPTP mutant mice. To test this hypothesis, we generated mice lacking both RPTP- $\sigma$ and RPTP- $\delta$. Here, we report that RPTP- $\sigma / \delta$ double-mutant mice exhibit a dramatic neuromuscular phenotype, with complete absence of movement, absence of breathing, and death shortly after birth. Histological analysis confirmed that the lungs fail to inflate in the double mutants (Fig. 2 ), likely because of inadequate innervation of the diaphragm (Figs. 6, 7). Notably, both RPTP- $\sigma^{-1-} / \delta^{+/-}$and RPTP $\sigma^{+1-} /$ $\delta^{-1-}$ mice exhibit reduced average life spans compared with either single mutant, suggesting some complementary function. RPTP $-\sigma / \delta$ double mutants also exhibited histological defects in the dermis, brown adipose tissue, and skeletal muscle (Fig. 3). Aberrant innervation by motoneurons is a likely cause of the skeletal muscle defects found in RPTP- $\sigma / \delta$ double mutants. However, we have not excluded the possibility of other roles for RPTP- $\sigma$ and RPTP- $\delta$, because both are expressed by mesodermal tissues during embryogenesis (Schaapveld et al., 1998).

Consistent with the complete absence of movement in RPTP$\sigma / \delta$ double mutants, histological examination of the embryonic spinal cord revealed that the majority of ChAT-immunopositive motoneurons were lost by E18.5 (Fig. 5D,F). However, at E13, the number of Islet-1/2-immunopositive motoneurons observed in RPTP- $\sigma / \delta$ double mutants was indistinguishable from wild type (Fig. $5 E$ ), suggesting that motoneuron loss is linked to defects in the late stages of axon extension, rather than altered motoneuron differentiation or development. This hypothesis is supported by our findings that phrenic axons in the double mutant appear to exit the spinal cord normally at E12 and appropriately extend toward the diaphragm (Fig. $6 B$ ), yet at E13.5, the terminal axonal branches that normally contact the diaphragm are severely stunted in the double mutants (Fig. 6E,F). By E15.5, the branches are absent (Fig. 7E,F) and presumably have been retracted. This interpretation is supported by our observation of a similar distribution of residual branches in the two E13.5 RPTP$\sigma / \delta$ double mutants examined (Fig. $6 F$, black arrowheads). Consistent with retraction of these axons at E15.5, the loss of mo- 
toneuron cell bodies was clearly evident by E18.5 (Fig. 5D,F). These results suggest that spinal motoneurons are lost in the double mutants as a consequence of their inability to establish appropriate contacts with muscle targets.

Our analyses reveal the absence of specific phrenic nerve branches in RPTP- $\sigma / \delta$ double mutants and reduced branching in RPTP- $\sigma^{+1-} / \delta^{-1-}$ and RPTP- $\sigma^{-1-} / \delta^{+1-}$ (Fig. 7I). These results suggest that the absence of RPTP- $\sigma$ and RPTP- $\delta$ may suppress the ability of axons to defasciculate from the phrenic nerve. Fasciculation is regulated by the relative affinity of the interactions between neighboring axons, and the affinity between an axon and its immediate environment. Interestingly, axon guidance defects with similarities to what we report here have been observed as a result of RPTP loss-of-function mutations in Drosophila. Loss of DLAR function, the Drosophila ortholog of both RPTP- $\sigma$ and RPTP- $\delta$, causes SNb motoneurons to fail to recognize appropriate muscle targets and generates errors in synapse formation (Krueger et al., 1996). Furthermore, mutation of the Drosophila RPTPs DPTP99A and DPTP69D results in misdirected motoneuron axon growth, defects in motoneuron axon defasciculation, and causes growth cones to stall as they approach muscle targets (Desai et al., 1996). These RPTP loss-of-function mutations in Drosophila produced defects in motoneuron axon guidance similar to those produced by CAM gain of function mutations (Lin and Goodman, 1994; Nose et al., 1994). Moreover, using RNA interference in the chick embryo, Stepanek et al. (2005) provided evidence that dorsal motor nerve fasciculation is disrupted by knock-down of either RPTP- $\sigma$ or RPTP- $\delta$. Thus, it is tempting to speculate that RPTP- $\sigma$ and RPTP- $\delta$ play a conserved role during mouse neural development, tempering adhesive interactions, thereby allowing motoneurons to appropriately defasciculate, extend, and make synaptic connections.

Quantitative analyses indicated that RPTP- $\sigma^{+/-} / \delta^{-/-}$and RPTP- $\sigma^{-1-} / \delta^{+/-}$mutants exhibited intermediate phenotypes in motoneuron survival and phrenic nerve branching, whereas no significant defect in either of the RPTP- $\sigma$ or RPTP- $\delta$ single mutants was detected (Figs. 5, 7I). These results provide strong evidence that RPTP- $\sigma$ and RPTP- $\delta$ complement each other functionally during axon targeting by mammalian motoneurons.

In contrast to the severe motoneuron defects reported, we have not observed abnormal phenotypes in sensory neurons, such as DRG neurons, nor in sympathetic neurons. RPTP- $\sigma$ is expressed by both motoneurons and sensory neurons. Motoneurons express RPTP- $\delta$ but not LAR, whereas the converse is the case for sensory neurons (Sommer et al., 1997; Schaapveld et al., 1998), suggesting that LAR may be able to compensate for the loss of RPTP- $\sigma$ in sensory neurons in the double mutant. Interestingly, recent findings indicate that RPTP- $\sigma$ and LAR influence
E15.5

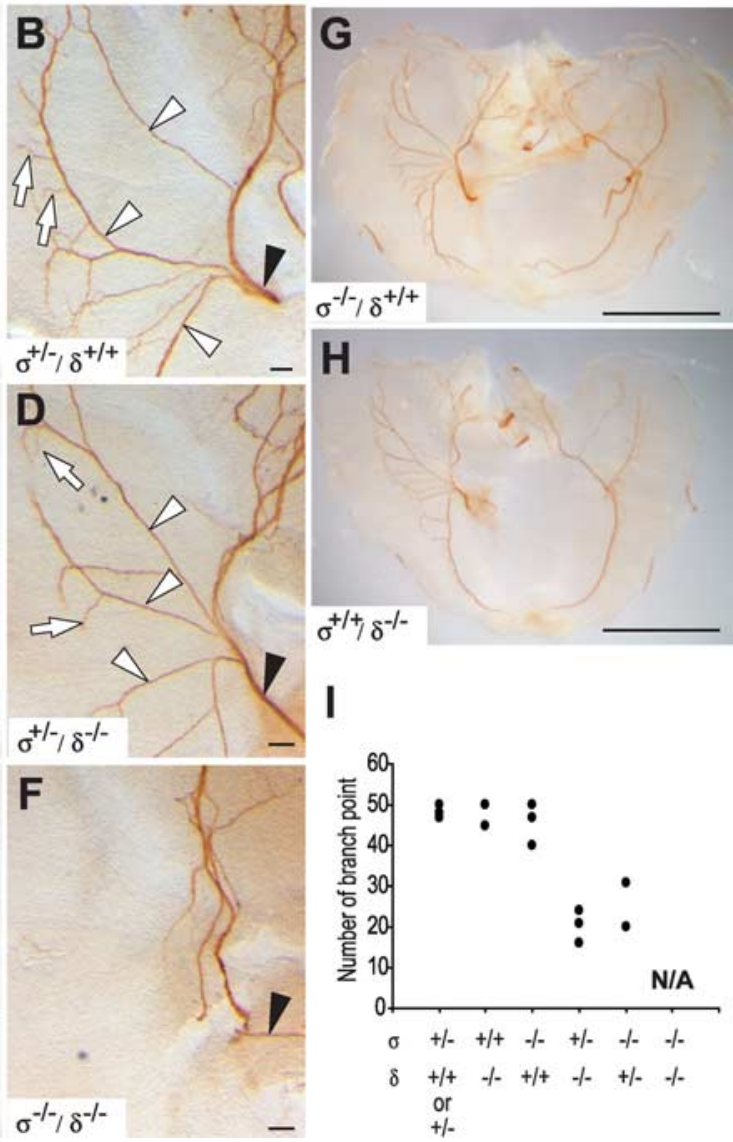

Figure 7. Complete absence of sternocostal nerves in RPTP- $\sigma / \delta$ double mutants at E15.5. Diaphragms stained with antineurofilament antibodies (2H3) at E15.5 are shown $(\boldsymbol{A}-\boldsymbol{H}) . \boldsymbol{B}, \boldsymbol{D}, \boldsymbol{F}$, High-magnification views of the frames in $\boldsymbol{A}, \boldsymbol{C}$, and $\boldsymbol{E}$. In

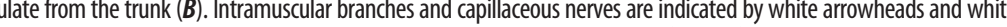
政, the intram double-mutant littermates ( $\boldsymbol{B}, \boldsymbol{D}, \boldsymbol{F}$; indicated by arrowhead). The innervation of the diaphragm in RPTP- $\sigma$ and RPTP- $\delta$ single-mutant 3), RPTP- $\sigma^{+/+} / \delta^{-1-}(n=2), \mathrm{RPTP}-\sigma^{-1-} / \delta^{+/+}(n=3), \mathrm{RPTP}-\sigma^{+/-} / \delta^{-1-}(n=3), \mathrm{RPTP}-\sigma^{-1-} / \delta^{+/-}(n=2)$ is illustrated in I. Scale bars: $\boldsymbol{A}, \boldsymbol{C}, \boldsymbol{E}, \boldsymbol{G}, \boldsymbol{H}, 1 \mathrm{~mm} ; \boldsymbol{B}, \boldsymbol{D}, \boldsymbol{F}, 100 \mu \mathrm{m}$.

axon regeneration in the adult CNS. The absence of LAR delayed axonal regeneration in vivo after injury to the sciatic nerve, a mixed sensory and motor nerve (Xie et al., 2001; Van der Zee et al., 2003). In contrast, in the RPTP- $\sigma$ mutant mice, axon regeneration in the sciatic, facial, and optic nerves was enhanced after axotomy (McLean et al., 2002; Thompson et al., 2003; Saphieha et al., 2005). These findings imply that, although LAR-RPTPs may sometimes exhibit redundant functions, the expression of different LAR-RPTPs may also have different functional consequences in some neuronal cell types.

Although the ligands and signal transduction mechanisms associated with LAR-RPTPs are not well understood, recent studies have provided evidence that the extracellular domain of cRPTP- $\sigma$ binds to matrix-associated heparan sulfate proteoglycans (HSPGs) (Haj et al., 1999; Aricescu et al., 2002), cues that influence axon guidance and play multiple essential roles during neural development (Inatani et al., 2003). The cRPTP- $\sigma$ extracellular domain also binds developing skeletal myotubes, although the putative ligand involved has not been identified (SajnaniPerez et al., 2003). The extracellular matrix laminin-nidogen complex has also been identified as a ligand for the LAR-FNIII 
Table 2. Primary phenotypes in RPTP- $\sigma / \delta$ double mutants

\begin{tabular}{|c|c|c|c|c|c|c|c|c|}
\hline \multirow[b]{3}{*}{ Genotype $(\sigma \cdot \delta)$} & \multirow{3}{*}{$\frac{\text { Paralysis }}{\frac{\text { E18.5 }}{\text { Pen (\%) }}}$} & \multirow{3}{*}{$\begin{array}{l}\text { Diaphragm dystrophy }^{a} \\
\text { E16.5-E18.5 } \\
\text { Pen (\%) }\end{array}$} & \multicolumn{2}{|c|}{ Aberrant phrenic nerve projection $^{b}$} & \multicolumn{4}{|c|}{ Decreased number of motoneurons } \\
\hline & & & \multirow{2}{*}{$\frac{\mathrm{E} 12}{\operatorname{Pen}(\%)}$} & \multirow{2}{*}{$\frac{\text { E13.5-E18.5 }}{\operatorname{Pen}(\%)}$} & \multicolumn{2}{|l|}{$\mathrm{E} 13$} & \multicolumn{2}{|l|}{ E18.5 } \\
\hline & & & & & $\operatorname{Pen}^{C}(\%)$ & $\operatorname{Red}(\%)$ & $\operatorname{Pen}^{C}(\%)$ & $\operatorname{Red}(\%)$ \\
\hline$+1+\cdot+1+$ & $0(7)$ & $0(4)$ & $0(2)$ & $0(5)$ & $0(5)$ & $0(5)$ & $0(4)$ & $0(4)$ \\
\hline$+1-\cdot+1+$ & $0(9)$ & $0(7)$ & - & $0(4)$ & - & - & - & - \\
\hline$-1-\cdot+1+$ & $0(5)$ & $0(2)$ & - & $0(7)$ & - & - & $0(2)$ & $0(2)$ \\
\hline$+1+\cdot+1-$ & $0(12)$ & $0(7)$ & $0(2)$ & $0(2)$ & - & - & - & - \\
\hline$+1-\cdot+1-$ & $0(27)$ & $0(19)$ & - & $0(1)$ & - & - & - & - \\
\hline$-1-\cdot+1-$ & $0(8)$ & $0(5)$ & - & $100^{d}(4)$ & - & - & $50(4)$ & $30(4)$ \\
\hline$+1+\cdot-1-$ & $0(9)$ & $0(5)$ & - & $0(6)$ & - & - & $0(3)$ & $0(3)$ \\
\hline$+1-\cdot-1-$ & $0(10)$ & $0(7)$ & - & $100^{d}(5)$ & - & - & $0(2)$ & $0(2)$ \\
\hline$-1-\cdot-1-$ & $100(15)$ & $100(6)$ & $0(3)$ & $100^{e}(7)$ & $0(3)$ & $0(3)$ & $100(4)$ & $85(4)$ \\
\hline
\end{tabular}

The number of animals analyzed is indicated in parentheses. Pen (\%), Percentage of penetrance; Red (\%), percentage of reduction compared with control animals; -, data are not available.

${ }^{a}$ Scored using histological sections at E16.5 and dissected diaphragms at E18.5.

${ }^{b}$ Scored using whole-mount anti-NF-stained diaphragms.

'Scored positive if statistically significant by Student's $t$ test $(p<0.05)$ against control animals.

${ }^{d}$ Showing less branching phenotype.

eShowing loss of sternocostal (intramuscular) nerves.

domain 5 (FN5) (O'Grady et al., 1998). This domain of LAR is highly conserved in all LAR-RPTPs, implicating lamininnidogen as a potential ligand for RPTP- $\sigma$ and RPTP- $\delta$ as well. Notably, laminins make numerous contributions to neural development, including influencing nerve-muscle synapse formation (Colognato and Yurchenco, 2000).

The intracellular domains of LAR-RPTPs are reported to interact with $\alpha$-Liprins (LAR interacting proteins) (Pulido et al., 1995) and $\beta$-catenin (Kypta et al., 1996; Muller et al., 1999), and these interactions are implicated in the maintenance of hippocampal excitatory synapses (Dunah et al., 2005). The other known mechanisms of downstream signal transduction regulated by LAR-RPTPs point to a role in the control of actin cytoskeletal organization. For example, the DH-GEF (Dblhomology guanine nucleotide exchange factor) Trio, a key regulator of the small Rho GTPase, regulates actin dynamics in axon growth cones (Lin and Greenberg, 2000) and is functionally downstream of Drosophila DLAR (Bateman et al., 2000). Furthermore, Trio binds Abelson tyrosine kinase (Abl) and Enabled (Ena), both of which are DLAR substrates (Wills et al., 1999). Reducing Trio activity potentiates the motor axon guidance defects produced by DLAR loss of function, which is consistent with Trio collaborating with DLAR during axon guidance (Bateman et al., 2000). Interestingly, mice lacking Trio exhibit phenotypic defects similar to those reported here for RPTP- $\sigma / \delta$ double mutants. These include deficiencies in muscle development (O'Brien et al., 2000), which are consistent with the RPTP- $\sigma / \delta$ doublemutant phenotypes, suggesting that the functional relationship between these genes may be conserved in mammalian neural development. We provide evidence that RPTP- $\sigma$ and RPTP- $\delta$ play functionally complementary roles during murine neural development and together make an essential contribution to appropriate motoneuron targeting. These findings identify a conserved role for the LAR subfamily of RPTPs, regulating motoneuron axon extension in both invertebrates and vertebrates.

\section{References}

Aricescu AR, McKinnell IW, Halfter W, Stoker AW (2002) Heparan sulfate proteoglycans are ligands for receptor protein tyrosine phosphatase sigma. Mol Cell Biol 22:1881-1892.

Banks GB, Noakes PG (2002) Elucidating the molecular mechanisms that underlie the target control of motoneuron death. Int J Dev Biol 46:551-558.

Bateman J, Shu H, Van Vactor D (2000) The guanine nucleotide exchange factor trio mediates axonal development in the Drosophila embryo. Neuron 26:93-106.

Beltran PJ, Bixby JL (2003) Receptor protein tyrosine phosphatases as mediators of cellular adhesion. Front Biosci 8:d87-d99.

Brady-Kalnay SM, Tonks NK (1995) Protein tyrosine phosphatases as adhesion receptors. Curr Opin Cell Biol 7:650-657.

Brandon EP, Lin W, D'Amour KA, Pizzo DP, Dominguez B, Sugiura Y, Thode S, Ko CP, Thal LJ, Gage FH, Lee KF (2003) Aberrant patterning of neuromuscular synapses in choline acetyltransferase-deficient mice. J Neurosci 23:539-549.

Clandinin TR, Lee CH, Herman T, Lee RC, Yang AY, Ovasapyan S, Zipursky SL (2001) Drosophila LAR regulates R1-R6 and R7 target specificity in the visual system. Neuron 32:237-248.

Colognato H, Yurchenco PD (2000) Form and function: the laminin family of heterotrimers. Dev Dyn 218:213-234.

Desai C, Purdy J (2003) The neural receptor protein tyrosine phosphatase DPTP69D is required during periods of axon outgrowth in Drosophila. Genetics 164:575-588.

Desai CJ, Popova E, Zinn K (1994) A Drosophila receptor tyrosine phosphatase expressed in the embryonic CNS and larval optic lobes is a member of the set of proteins bearing the "HRP" carbohydrate epitope. J Neurosci 14:7272-7283.

Desai CJ, Gindhart Jr JG, Goldstein LS, Zinn K (1996) Receptor tyrosine phosphatases are required for motor axon guidance in the Drosophila embryo. Cell 84:599-609.

Desai CJ, Krueger NX, Saito H, Zinn K (1997) Competition and cooperation among receptor tyrosine phosphatases control motoneuron growth cone guidance in Drosophila. Development 124:1941-1952.

Dodd J, Morton SB, Karagogeos D, Yamamoto M, Jessell TM (1988) Spatial regulation of axonal glycoprotein expression on subsets of embryonic spinal neurons. Neuron 1:105-116.

Dunah AW, Hueske E, Wyszynski M, Hoogenraad CC, Jaworski J, Pak DT, Simonetta A, Liu G, Sheng M (2005) LAR receptor protein tyrosine phosphatases in the development and maintenance of excitatory synapses. Nat Neurosci 8:458-467.

Elchebly M, Wagner J, Kennedy TE, Lanctot C, Michaliszyn E, Itie A, Drouin J, Tremblay ML (1999) Neuroendocrine dysplasia in mice lacking protein tyrosine phosphatase sigma. Nat Genet 21:330-333.

Garrity PA, Lee CH, Salecker I, Robertson HC, Desai CJ, Zinn K, Zipursky SL (1999) Retinal axon target selection in Drosophila is regulated by a receptor protein tyrosine phosphatase. Neuron 22:707-717.

Haj F, McKinnell I, Stoker A (1999) Retinotectal ligands for the receptor tyrosine phosphatase CRYPalpha. Mol Cell Neurosci 14:225-240.

Helmbacher F, Schneider-Maunoury S, Topilko P, Tiret L, Charnay P (2000) Targeting of the EphA4 tyrosine kinase receptor affects dorsal/ventral pathfinding of limb motor axons. Development 127:3313-3324.

Inatani M, Irie F, Plump AS, Tessier-Lavigne M, Yamaguchi Y (2003) Mammalian brain morphogenesis and midline axon guidance require heparan sulfate. Science 302:1044-1046. 
Johnson KG, Holt CE (2000) Expression of CRYP-alpha, LAR, PTP-delta, and PTP-rho in the developing Xenopus visual system. Mech Dev 92:291-294.

Johnson KG, Van Vactor D (2003) Receptor protein tyrosine phosphatases in nervous system development. Physiol Rev 83:1-24.

Krueger NX, Van Vactor D, Wan HI, Gelbart WM, Goodman CS, Saito H (1996) The transmembrane tyrosine phosphatase DLAR controls motor axon guidance in Drosophila. Cell 84:611-622.

Kypta RM, Su H, Reichardt LF (1996) Association between a transmembrane protein tyrosine phosphatase and the cadherin-catenin complex. J Cell Biol 134:1519-1529.

Lin DM, Goodman CS (1994) Ectopic and increased expression of Fasciclin II alters motoneuron growth cone guidance. Neuron 13:507-523.

Lin MZ, Greenberg ME (2000) Orchestral maneuvers in the axon: trio and the control of axon guidance. Cell 101:239-242.

Maurel-Zaffran C, Suzuki T, Gahmon G, Treisman JE, Dickson BJ (2001) Cell-autonomous and -nonautonomous functions of LAR in R7 photoreceptor axon targeting. Neuron 32:225-235.

McLean J, Batt J, Doering LC, Rotin D, Bain JR (2002) Enhanced rate of nerve regeneration and directional errors after sciatic nerve injury in receptor protein tyrosine phosphatase sigma knock-out mice. J Neurosci 22:5481-5491.

Misgeld T, Burgess RW, Lewis RM, Cunningham JM, Lichtman JW, Sanes JR (2002) Roles of neurotransmitter in synapse formation: development of neuromuscular junctions lacking choline acetyltransferase. Neuron 36:635-648.

Mizuno K, Hasegawa K, Ogimoto M, Katagiri T, Yakura H (1994) Developmental regulation of gene expression for the MPTP delta isoforms in the central nervous system and the immune system. FEBS Lett 355:223-228.

Muller T, Choidas A, Reichmann E, Ullrich A (1999) Phosphorylation and free pool of beta-catenin are regulated by tyrosine kinases and tyrosine phosphatases during epithelial cell migration. J Biol Chem 274:10173-10183.

Newsome TP, Asling B, Dickson BJ (2000) Analysis of Drosophila photoreceptor axon guidance in eye-specific mosaics. Development 127:851-860.

Nose A, Takeichi M, Goodman CS (1994) Ectopic expression of connectin reveals a repulsive function during growth cone guidance and synapse formation. Neuron 13:525-539.

O'Brien SP, Seipel K, Medley QG, Bronson R, Segal R, Streuli M (2000) Skeletal muscle deformity and neuronal disorder in Trio exchange factordeficient mouse embryos. Proc Natl Acad Sci USA 97:12074-12078.

O'Grady P, Thai TC, Saito H (1998) The laminin-nidogen complex is a ligand for a specific splice isoform of the transmembrane protein tyrosine phosphatase LAR. J Cell Biol 141:1675-1684.

Pfaff SL, Mendelsohn M, Stewart CL, Edlund T, Jessell TM (1996) Requirement for LIM homeobox gene Isl1 in motor neuron generation reveals a motor neuron-dependent step in interneuron differentiation. Cell 84:309-320.

Pulido R, Serra-Pages C, Tang M, Streuli M (1995) The LAR/PTP delta/PTP sigma subfamily of transmembrane protein-tyrosine-phosphatases: multiple human LAR, PTP delta, and PTP sigma isoforms are expressed in a tissue-specific manner and associate with the LAR-interacting protein LIP. 1. Proc Natl Acad Sci USA 92:11686-11690.

Sajnani-Perez G, Chilton JK, Aricescu AR, Haj F, Stoker AW (2003) Isoform-specific binding of the tyrosine phosphatase PTPsigma to a ligand in developing muscle. Mol Cell Neurosci 22:37-48.

Saphieha PS, Duplan L, Uetani N, Joly S, Tremblay ML, Kennedy TE, Di Polo A (2005) Receptor protein tyrosine phosphatase sigma inhibits axon regrowth in the adult injured CNS. Mol Cell Neurosci 28:625-635.
Schaapveld RQ, Schepens JT, Bachner D, Attema J, Wieringa B, Jap PH, Hendriks WJ (1998) Developmental expression of the cell adhesion molecule-like protein tyrosine phosphatases LAR, RPTPdelta and RPTPsigma in the mouse. Mech Dev 77:59-62.

Sommer L, Rao M, Anderson DJ (1997) RPTP delta and the novel protein tyrosine phosphatase RPTP psi are expressed in restricted regions of the developing central nervous system. Dev Dyn 208:48-61.

Stepanek L, Stoker AW, Stoeckli E, Bixby JL (2005) Receptor tyrosine phosphatases guide vertebrate motor axons during development. J Neurosci 25:3813-3823.

Stoker AW, Gehrig B, Haj F, Bay BH (1995) Axonal localisation of the CAM-like tyrosine phosphatase CRYP alpha: a signalling molecule of embryonic growth cones. Development 121:1833-1844.

Sun Q, Bahri S, Schmid A, Chia W, Zinn K (2000) Receptor tyrosine phosphatases regulate axon guidance across the midline of the Drosophila embryo. Development 127:801-812.

Thompson KM, Uetani N, Manitt C, Elchebly M, Tremblay ML, Kennedy TE (2003) Receptor protein tyrosine phosphatase sigma inhibits axonal regeneration and the rate of axon extension. Mol Cell Neurosci 23:681-692.

Tian SS, Tsoulfas P, Zinn K (1991) Three receptor-linked protein-tyrosine phosphatases are selectively expressed on central nervous system axons in the Drosophila embryo. Cell 67:675-680.

Tsuchida T, Ensini M, Morton SB, Baldassare M, Edlund T, Jessell TM, Pfaff SL (1994) Topographic organization of embryonic motor neurons defined by expression of LIM homeobox genes. Cell 79:957-970.

Uetani N, Kato K, Ogura H, Mizuno K, Kawano K, Mikoshiba K, Yakura H, Asano M, Iwakura Y (2000) Impaired learning with enhanced hippocampal long-term potentiation in PTPdelta-deficient mice. EMBO J 19:2775-2785.

Van der Zee CE, Man TY, Van Lieshout EM, Van der Heijden I, Van Bree M, Hendriks WJ (2003) Delayed peripheral nerve regeneration and central nervous system collateral sprouting in leucocyte common antigen-related protein tyrosine phosphatase-deficient mice. Eur J Neurosci 17:991-1005.

Van Lieshout EM, Van der Heijden I, Hendriks WJ, Van der Zee CE (2001) A decrease in size and number of basal forebrain cholinergic neurons is paralleled by diminished hippocampal cholinergic innervation in mice lacking leukocyte common antigen-related protein tyrosine phosphatase activity. Neuroscience 102:833-841.

Wallace MJ, Batt J, Fladd CA, Henderson JT, Skarnes W, Rotin D (1999) Neuronal defects and posterior pituitary hypoplasia in mice lacking the receptor tyrosine phosphatase PTPsigma. Nat Genet 21:334-338.

Wills Z, Bateman J, Korey CA, Comer A, Van Vactor D (1999) The tyrosine kinase $\mathrm{Abl}$ and its substrate enabled collaborate with the receptor phosphatase Dlar to control motor axon guidance. Neuron 22:301-312.

Xie Y, Yeo TT, Zhang C, Yang T, Tisi MA, Massa SM, Longo FM (2001) The leukocyte common antigen-related protein tyrosine phosphatase receptor regulates regenerative neurite outgrowth in vivo. J Neurosci 21:5130-5138.

Yan H, Grossman A, Wang H, D'Eustachio P, Mossie K, Musacchio JM, Silvennoinen O, Schlessinger J (1993) A novel receptor tyrosine phosphatase-sigma that is highly expressed in the nervous system. J Biol Chem 268:24880-24886.

Yeo TT, Yang T, Massa SM, Zhang JS, Honkaniemi J, Butcher LL, Longo FM (1997) Deficient LAR expression decreases basal forebrain cholinergic neuronal size and hippocampal cholinergic innervation. J Neurosci Res $47: 348-360$. 